\title{
THE HAEMAGGLUTINATION TEST FOR TOXOPLASMA ANTIBODIES
}

\author{
BY \\ R. G. MITCHELL AND C. A. GREEN \\ From the Department of Bacteriology, Royal Victoria Infirmary, Newcastle-upon-Tyne
}

(RECEIVED FOR PUBLICATION FEBRUARY 10, 1960)

Four hundred and forty-six patients' sera from a hospital blood transfusion department in Newcastle were examined for toxoplasma antibodies by a haemagglutination test.

Forty per cent. of the sera gave positive reactions, and an increase in the percentage of positive sera was found with increasing age, rising to over $60 \%$ at the age of 70 and over. A wide range of titres was demonstrated amongst positive cases, the highest titres approaching those obtained in two cases of active toxoplasmosis.

In a separate survey, no quantitative agreement was found between dye test titres and haemagglutination titres.

As knowledge of toxoplasmosis has increased, efforts have been made to improve and extend the range of specific diagnostic tests. At present, the test most commonly employed is the Sabin-Feldman dye test or one of its modifications. This is technically exacting to perform, and requires the presence of live toxoplasmas, as well as a supply of normal accessory factor serum which is often difficult to obtain. In the search for alternative methods, attempts have been made to develop a haemagglutination test for the presence of toxoplasma antibodies in serum. Bozdečh and Jíra (1958), using sensitized human group $\mathrm{O} R \mathrm{Rh}$-negative cells, concluded that the test was less sensitive even than the complement-fixation reaction. Jacobs and Lunde (1957) and Lunde and Jacobs (1958), using the tanned red cell technique of Boyden (1951), obtained results which corresponded well with dye test titres, but stressed the need for further work before it could become an established technique.

In the present investigation, we have attempted to confirm the value of the test, using it, after suitable modifications, to determine the incidence of toxoplasma antibodies in a hospital population provided by recipients' sera in a blood transfusion department.

\section{Materials and Methods}

The antigen was prepared from the peritoneal exudate of mice inoculated four days previously with a strain of toxoplasma known to have been of constant virulence for mice over at least two years. The pooled exudate was centrifuged for $30 \mathrm{~min}$. at 3,000 r.p.m. and the supernatant discarded. The sediment was washed twice in normal saline, and resuspended in phosphate buffered saline (see below) to the original volume of the exudate. The toxoplasmas were disrupted by ultrasonic vibration at $20 \mathrm{Kc}$ for one hour, using a Mullard-M.S.E. disintegrator. Cellular debris was removed by centrifuging for $30 \mathrm{~min}$. at 3,000 r.p.m. The supernatant constituted the neat antigen. It was tubed off in small amounts sufficient for each batch of tests, and stored at $-20^{\circ} \mathrm{C}$.

The haemagglutination test proper was based on the technique of Boyden and Sorkin (1955). Instead of sheep cells, human group $\mathbf{O}$ Rh-negative cells in citric aciddextrose solution were used, as described by Roitt and Doniach (1958). Apart from their ready availability in hospital and freedom from contamination, their use avoided the necessity of absorbing large numbers of sera with species-different packed cells before the test. Occasionally cells were obtained freshly by venepuncture.

Normal saline buffered with a phosphate mixture, prepared according to Stavitsky (1954), was used at all stages of the test.

The serum-saline "stabilizer" used to suspend the sensitized cells and to dilute the test sera was $2 \%$ human AB Rh-positive serum in buffered saline. The serum was previously tested and found negative for toxoplasma antibodies.

The red cells were washed six times in saline and made up to a $2 \frac{1}{2} \%$ suspension in saline. The cells were tanned at $37^{\circ} \mathrm{C}$. for $15 \mathrm{~min}$. using 1 volume of $1 / 40,000$ tannic acid (Merck) in saline. After a single wash in 2 volumes of saline, the cells were reconstituted to a $2 \frac{1}{2} \%$ suspension. One volume of suitably diluted antigen (see below) was added and sensitization carried out for approximately $15 \mathrm{~min}$. at room temperature. The tanned sensitized cells were washed twice in 2 volumes of $0.5 \%$ serum-saline, and resuspended in $2 \%$ serum-saline to a $0.5 \%$ suspension. Cells sensitized in this way could not be relied upon to retain constant activity for more than one day unless $0.25 \%$ formalin was added to the serumsaline. If the formolized cells were left overnight before use, they were subsequently found to give constant titres with the same positive control serum for at least four days, and on one occasion were found to work satisfactorily for up to two weeks when stored at $4^{\circ} \mathrm{C}$. 
Haemagglutination was carried out in small rimless tubes ( $1 \frac{1}{8}$ in. $\times \frac{3}{16}$ in.) placed at an angle of $50^{\circ}$ to the horizontal as described by Boyden and Sorkin (1955), and set up in a row of 12 tubes for each test serum. New, unwashed tubes were found suitable and were discarded after use. Each tube received $\mathbf{0 . 2} \mathrm{ml}$. of sensitized cells. Test sera were diluted 1 in 10 in $2 \%$ serum-saline. Serum, $0.2 \mathrm{ml}$., was added to the first tube, and serial twofold dilutions made along the row, giving a range of serum dilutions 1 in 10 to 1 in 20,480. The end-point was taken as the last tube in which cells adhered appreciably to the back of the tube. The results could usually be read approximately two hours after setting up the test at room temperature, and were expressed as the reciprocal of the final dilution. If all sera were previously inactivated at $58^{\circ} \mathrm{C}$. for $15 \mathrm{~min}$., and the racks stored at $4^{\circ} \mathrm{C}$. overnight, the results could conveniently be read the following morning.

Multiple negative and positive control sera were used in the test. The titres obtained were arbitrarily related to a standard positive serum (dye test titre 1 in 70) used throughout the investigation. The strength of antigen employed was checked and if necessary adjusted for each batch of cells so that the titre given by this serum fell within the range six to eight tubes. This standard was conveniently chosen so that the highest titres encountered in test sera rarely exceeded 12 tubes.
When testing large numbers of sera, a preliminary $\underline{\underline{ }}$ screening test was carried out to a three-tube dilution to separate positive from negative sera. In this way, positive $\stackrel{\bar{S}}{\rightarrow}$ sera collected over several weeks could be taken to their $\overline{0}$ final titres in one large batch, using a single preparation $\frac{C}{0}$ of cells, thereby obtaining the most uniform conditions $\frac{\bar{\sigma}}{\bar{s}}$ for quantitative testing.

\section{Results}

Four hundred and forty-six sera obtained during 1959 from the hospital blood transfusion department of the Royal Victoria Infirmary, Newcastle, $\vec{\omega}$ were examined, and of these $177(40 \%)$ gave positive $\stackrel{5}{\circ}$

TABLE I

\begin{tabular}{|c|c|c|c|c|c|c|c|c|}
\hline \multirow{2}{*}{ Titres } & \multicolumn{8}{|c|}{ Age in Years } \\
\hline & $0-9$ & $\begin{array}{c}10- \\
19\end{array}$ & $\begin{array}{l}20- \\
29\end{array}$ & $\begin{array}{c}30- \\
39\end{array}$ & $\begin{array}{l}40- \\
49\end{array}$ & $\begin{array}{l}50- \\
59\end{array}$ & $\begin{array}{c}60- \\
69\end{array}$ & $70+$ \\
\hline Negative & 31 & 42 & 45 & 32 & 36 & 39 & 22 & 22 \\
\hline $\begin{array}{l}20-40 \\
80-320 \\
640-\end{array}$ & $\begin{array}{l}2 \\
1\end{array}$ & $\begin{array}{l}2 \\
6\end{array}$ & $\begin{array}{l}4 \\
9\end{array}$ & $\begin{array}{r}1 \\
16\end{array}$ & $\begin{array}{r}3 \\
13\end{array}$ & $\begin{array}{r}1 \\
14\end{array}$ & $\begin{array}{r}8 \\
17\end{array}$ & $\begin{array}{r}6 \\
23\end{array}$ \\
\hline 2,120 & 1 & 6 & 6 & 5 & 7 & 8 & 8 & 6 \\
\hline $\begin{aligned} 20,480 \\
20,480\end{aligned}$ & $\begin{array}{l}0 \\
0\end{array}$ & $\begin{array}{l}1 \\
0\end{array}$ & $\begin{array}{l}\mathbf{0} \\
\mathbf{0}\end{array}$ & $\begin{array}{l}0 \\
1\end{array}$ & $\begin{array}{l}1 \\
0\end{array}$ & $\begin{array}{l}0 \\
0\end{array}$ & $\begin{array}{l}0 \\
0\end{array}$ & $\begin{array}{l}1 \\
0\end{array}$ \\
\hline
\end{tabular}

\section{Haemagglutination Titres}
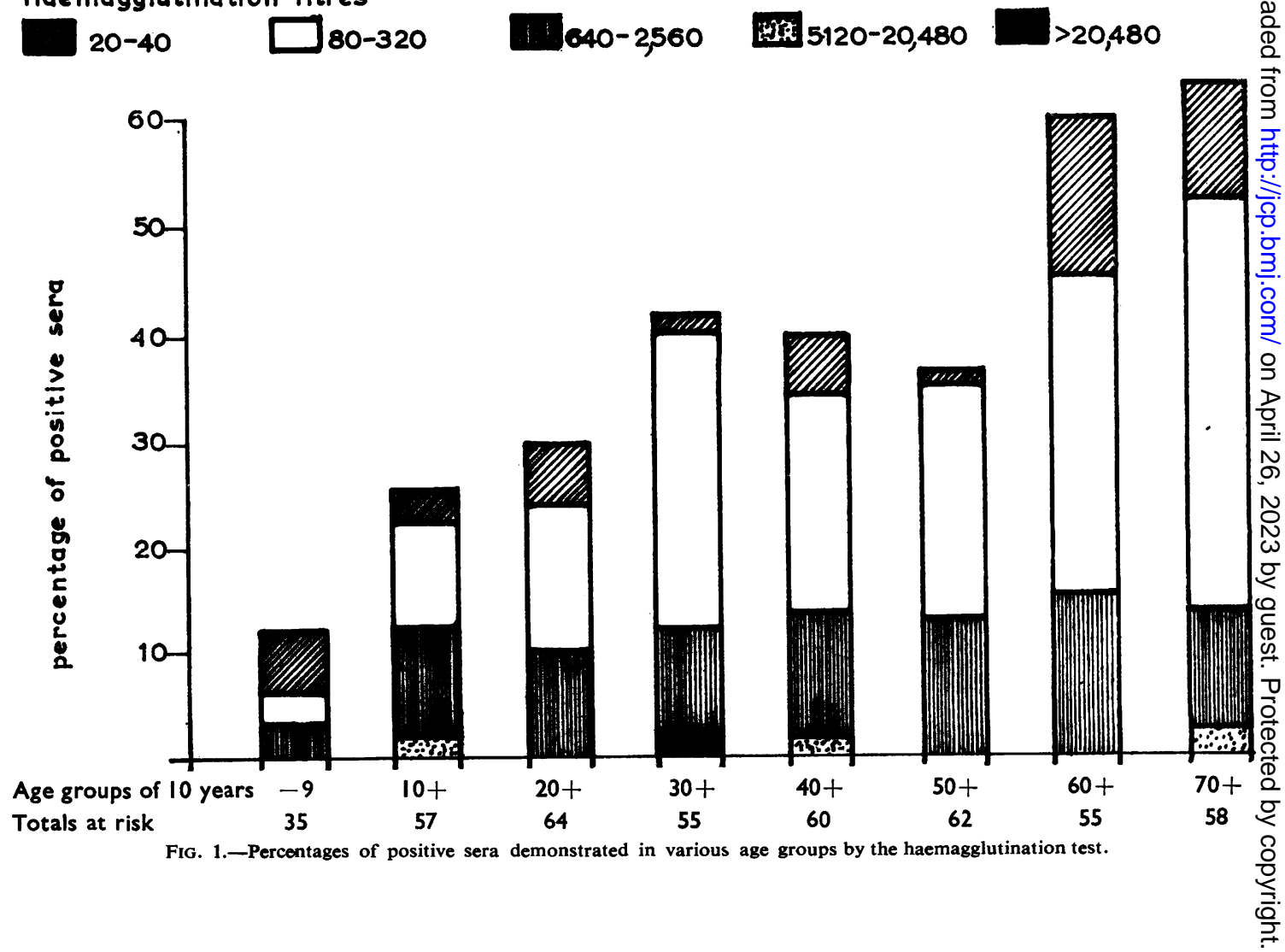


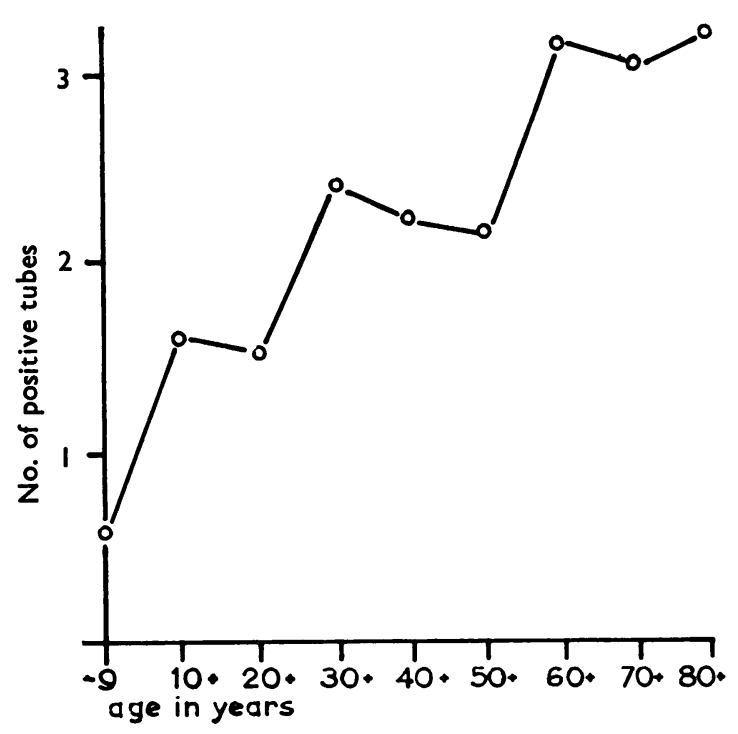

FIG. 2.-Average number of positive tubes per patient at risk in the various age groups.

reactions to a titre of $\mathbf{2 0}$ or more. Roughly equal numbers of sera were represented in the various age groups, and the absolute numbers and percentages of positive sera in the groups are given in Table $I$ and Fig. 1. Sera from children under the age of 6 months were excluded from the series, to eliminate the possibility of maternal transfer of antibodies.

The incidence of positive sera appeared to rise in step-like fashion from $11 \%$ in the age group 0-9 years to $62 \%$ in patients over the age of 70 . The same tendency is shown in Fig. 2, which expresses the average number of positive tubes per patient at risk in each age group. The highest titres are not encountered in any particular age group. The highest titre in the series, 40,960, was given by a serum from a patient aged 35 , whilst a titre of 10,240 was given by a serum from a 10 -year-old child.

Forty-three per cent. of 234 sera from females were positive compared with $39 \%$ of 186 sera from males.

The various blood groups were normally represented among the positive sera.

In a separate study, attempts were made to correlate haemagglutination titres with dye test titres. Of 73 sera received from source $A, 17$ gave a negative dye test (D.T.) of less than 1 in 4 , and a negative haemagglutination test (H.T.); 35 gave a positive D.T. with a positive H.T.; 20 gave a positive D.T. with a negative H.T., but only one serum gave a negative D.T. with a positive H.T. The highest D.T. titre of a serum giving a negative H.T. was 1 in 110 . No quantitative relationship was found when D.T. titres were plotted against H.T. titres (Fig. 3).

Of 25 sera from another source $B$, all with positive D.T. titres of 1 in 10 or more, 23 gave a positive

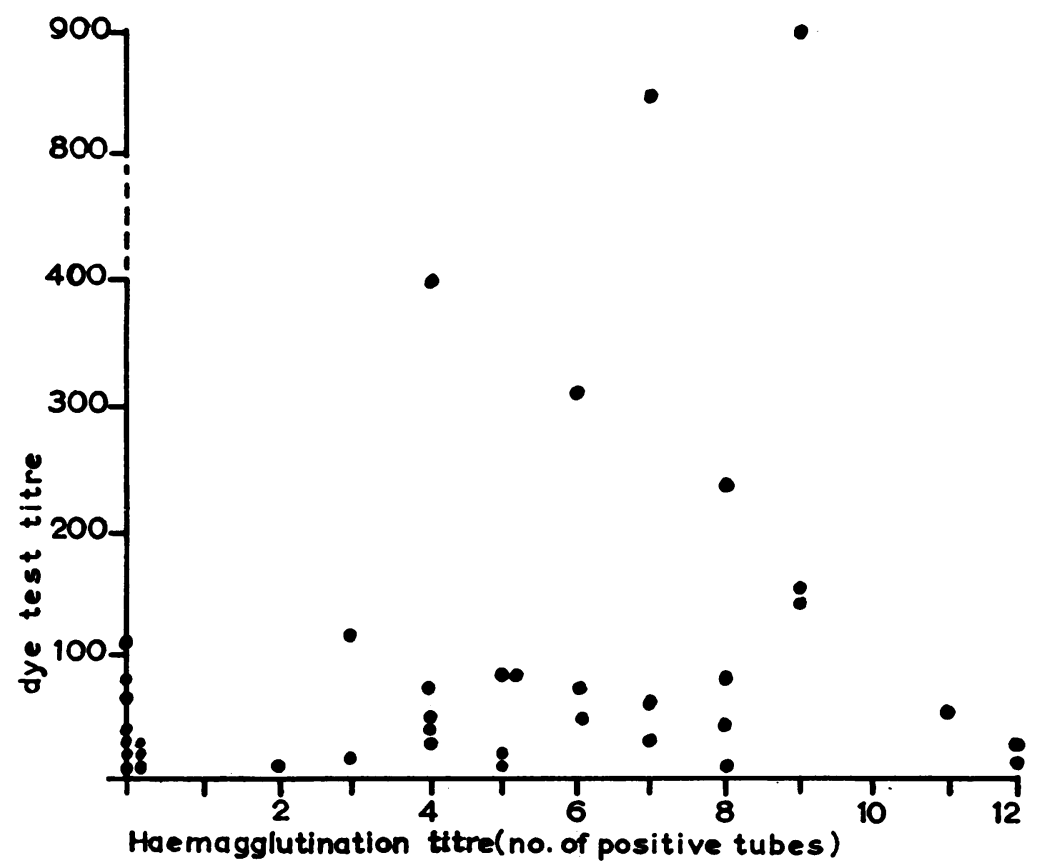

Fig. 3.-Sera from source $A$ : dye test titres and haemagglutination titres compared. 


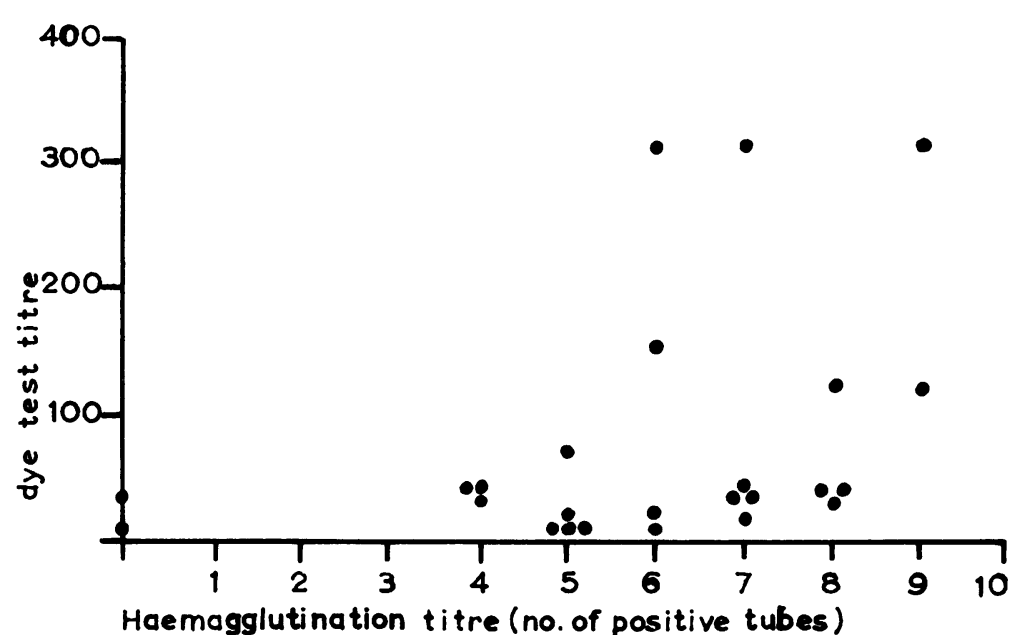

FIG. 4.-Sera from source B: dye test titres and haemagglutination titres compared.

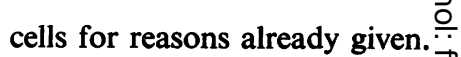
It was found unnecessary to $\overrightarrow{\bar{s}}$ alter the $p \mathrm{H}$ from 7.2 to 6.40 during sensitization. The sloped tube technique was used, $\frac{\bar{s}}{\frac{}{2}}$. partly to overcome the difficul- $\stackrel{\varnothing}{\Omega}$ ties of interpreting characteristic haemagglutination patterns at $\overrightarrow{0}$ the bottom of wide-bore tubes, $\stackrel{-}{-}$ and partly with the object of $\vec{\omega}$ increasing, if possible, the $\frac{\text { ? }}{8}$ sensitivity of the test.

Jacobs and Lunde use their $\vec{\omega}$ antigens at such a concentra- $\rightarrow$ tion that the haemagglutina- $\underset{\omega}{\omega}$ tion titre of a positive control $\vec{\circ}$ serum is the same as its dye $\stackrel{?}{?}$ test titre. They find close $\vec{c}$ agreement as to positivity and H.T., but there was again no quantitative correlation between D.T. titres and H.T. titres (Fig. 4). The two sera found negative by the H.T. had D.T. titres of 1 in 10 and 1 in 40.

\section{Discussion}

In trying to repeat the haemagglutination technique of Jacobs and Lunde, we were unable to produce potent antigens by the lysis of toxoplasmas in distilled water. Indeed, the organisms appeared to be surprisingly resistant to disruption even by repeated freezing and thawing. The method of ultrasonic disintegration finally adopted was suggested by Jacobs and Lunde (1957) themselves, and was previously used by Gronroos and Westphal (quoted by Cooney, Kimball, and Bauer, 1958), and by Hook and Faber (1957), who used this method in their studies on the nature of toxoplasma antigens. Incidentally we were able to confirm the finding of these last two authors that the fraction obtained from crude antigen by precipitation with ammonium sulphate at $30 \%$ saturation retains antigenic potency since it is able to sensitize red cells in the haemagglutination reaction.

Jacobs and Lunde considered that their antigens remained stable for periods of between five and 17 months when stored at $-15^{\circ} \mathrm{C}$. The antigens prepared by ultrasonic vibration showed a continuous loss of potency on storage at $-20^{\circ} \mathrm{C}$. over a period of eight weeks or less. Toxoplasmas in buffered saline stored for long periods at $-20^{\circ} \mathrm{C}$. and then disintegrated were found unsuitable for antigen preparation.

Although sheep cells worked satisfactorily in the test, it was found more convenient to use human titre of test sera using both methods, to within a $\vec{\theta}$ four-fold difference in haemagglutination titre in over $90 \%$ sera. We have not been able to confirm this with our modified technique. In a series of 73 sera, 20 with a positive dye test gave a negative haemagglutination test, although, as discussed below, the haemagglutination reaction is possibly $\stackrel{\square}{\square}$ more sensitive in detecting positive sera in a popu- $\stackrel{\varrho}{\Rightarrow}$ lation survey. This discrepancy may perhaps be due $\frac{\bar{O}}{3}$ to deterioration of sera following storage and $\frac{\Im}{\sigma}$ repeated investigation, and it appears advisable in future work to carry out both tests simultaneously, if possible in the same department. No quantitative? relationship was shown between the results of both -5 tests, and consequently no attempt has been made 3 . to standardize one test in terms of the other. There $\delta$ is no reason why these two tests should give parallel $₹$ results, any more than do the complement-fixation ㅇ reaction and the dye test, and it cannot be assumed $D$ that the dye test and haemagglutination test are을 measuring the same antibody components.

Beverley and Beattie (1954), using a modification of the Sabin-Feldman dye test in a survey of $581 \mathrm{~N}$ sera from "normal" persons in Sheffield, found ${ }^{N}$ that infection was rare in early life, but that over the age of 20 years approximately $25 \%$ of the populatione showed antibodies in their sera. There was no $\bar{\varnothing}$ further rise in incidence over the age of 20 . The $\stackrel{?}{+}$ percentage of positive sera in the present investi- $\frac{T}{T}$ gation is considerably higher, and continues to rise $\frac{\vec{P}}{\mathbb{D}}$ throughout life. However, we have examined fewer $\stackrel{\mathbb{P}}{\stackrel{P}{P}}$ sera, drawn from a hospital population in a different $\stackrel{\mathbb{Q}}{\Omega}$ part of the country, so that the two surveys cannot $\bar{Q}$ be directly compared. As it was possible that our $ᄋ$ higher incidence could be accounted for by the 
inclusion of active cases of toxoplasmosis, clinical details were sought from those patients giving the highest titres. Except for the instance of an 80-yearold woman with a haemagglutination titre of 5,120 , admitted to hospital with a haematemesis, who was found to have an ulnar neuritis and blindness in one eye-both conditions which might conceivably have been due to toxoplasmosis-there was nothing to suggest current infection. In any case, patients requiring urgent blood transfusion or about to undergo planned surgical procedures were primarily suffering from a totally dissimilar condition.

Sera from two patients with clinically active toxoplasmosis, and not included in the series, both gave haemagglutination titres of 160,000 . The upper range of titres demonstrated in the present survey closely approaches this high value, so that it may not prove possible to define the upper limit of normal values for this method. It does not appear that a given titre can be interpreted any more significantly in conjunction with the patient's age, since high titres may be encountered at all ages. This problem, which is essentially that of distinguishing between present and past infection, is of course met when interpreting dye test titres.

The haemagglutination test for toxoplasma antibodies is at any rate seen to be a safe and practical test. It is extremely sensitive, and indeed might be made less sensitive with advantage. If stable antigens can be prepared and distributed, the test should lend itself to greater standardization than is possible with the dye test, and warrants further investigation.

We are indebted to Mr. E. C. Elliott, F.I.M.L.T., for skilled technical assistance; to Professor C. P. Beattie and Dr. I. A. B. Cathie for providing sera of known dye test titre; and to Dr. G. B. Ludlam for his helpful comments on the paper.

\section{REFERENCES}

Beverley, J. K. A., and Beattie, C. P. (1954). J. Hyg. (Lond.), 52, 37. Boyden, S. V. (1951). J. exp. Med., 93, 107. and Sorkin, E. (1955). J. Immunol., 75, 15.

Bozdeč, V., and Jíra, J. (1958). Čas Lék čes., 97, 375. Cooney, Marion K., Kimball, Anne C., and Bauer, H. (1958). J. Immunol., 81, 177 .

Hook, W. A., and Faber, J. E. (1957). Exp. Parasit., 6, 449.

Jacobs, L., and Lunde, M. N. (1957). J. Parasit., 43, 308.

Lunde, M. N., and Jacobs, L. (1958). Amer. J. trop. Med. Hyg., 7, 523.

Roitt, I. M., and Doniach, Deborah (1958). Lancet, 2, 1027.

Stavitsky, A. B. (1954). J. Immunol., 72, 360. 